\title{
Cardiovascular Risk in Women from a Quilombo Settlement: The Effect of Aggregated Vulnerabilities
}

\author{
Deborah Carvalho Malta ${ }^{1}$ and Luisa Campos Caldeira Brant ${ }^{2}{ }^{\circledR}$ \\ Post-graduate Program in Public Health. School of Medicine. Universidade Federal de Minas Gerais, ${ }^{1}$ Belo Horizonte, MG - Brazil \\ School of Medicine. Universidade Federal de Minas Gerais, ${ }^{2}$ Belo Horizonte, MG - Brazil \\ Editorial referring to the article: Accuracy of the Simplified Version of the Global Risk Score in Detecting Cardiovascular Risk in Women from \\ Quilombola Communities in the State of Alagoas, Brazil
}

Cardiovascular risk (CVR) is a field of great relevance with a growing number of studies throughout the country due to the magnitude of cardiovascular diseases (CVD), which have caused nearly 18 million deaths in 2016 and represent $31 \%$ of worldwide deaths. ${ }^{1-3}$ In Brazil, CVD also lead the mortality and disability-adjusted life years (DALYs) rates, ${ }^{4.5}$ with negative effects on the quality of life of individuals, family members, and societies. ${ }^{3.5}$ It is noteworthy that CVD has an unequal effect on populations, with greater morbidity and mortality among low-income and least educated individuals. ${ }^{6}$ In this context, it is important to identify the modifiable risk factors (RF) associated with CVD, such as behavioral (tobacco, alcohol, unhealthy diet, sedentarism) and metabolic RF (obesity, diabetes, hypertension, dyslipidemia); given that the risk of death from CVD attributable to metabolic RF is $74 \%$, revealing great potential for prevention. ${ }^{7,8}$

CVR scores are important because evidence has shown that when RF are aggregated, they have synergistic effects on the risk of major adverse cardiovascular events (MACE). ${ }^{1,9}$ As such, CVR scores identify high-priority individuals for specific primary preventive interventions against MACE, making them cost-effective measures that are useful in primary care. ${ }^{19-11}$ Beyond the incentive for a healthy lifestyle, individuals with higher CVR should be offered statin prescriptions and be evaluated for hypertension treatment at a lower threshold. ${ }^{12}$ A meta-analysis showed that statins can prevent $23 \%$ (relative risk [RR] $0.7795 \%$ confidence interval

\section{Keywords}

Heart Disease Risk Factors; Health Vulnerability; Hypertension; Diabetes Mellitus; Obesity.
[CI] 0.71-0.84) of MACE. ${ }^{13}$ However, for primary prevention this benefit is positively correlated with CVR and non-highdensity lipoprotein (HDL) cholesterol values. ${ }^{13}$

The study conducted by Cavalcante et al. ${ }^{11}$ analyzed the CVR of 1015 women from Quilombo settlements in the state of Alagoas, Brazil, aged 19 to 59 years. Their work covers a gap in knowledge by collecting data from poor communities in the rural area of the Northeast region of Brazil, combining interview data with anthropometric, blood pressure, and laboratory measurements through a precise and appropriate methodology. The results indicated that $73.6 \%$ of the women were contemplated by the Bolsa Família Program, with a high prevalence of RF: hypertension $(22.3 \%)$, diabetes $(25.1 \%)$, and overweight and obesity (66.8\%). The authors highlight that these women live "in a scenario marked by a low socioeconomic level, precarious environmental conditions, and a high prevalence of food insecurity (74.0\%); and of the morbidities related to this context." ${ }^{\prime 11}$

Using the 2008 Framingham Heart Study's Global Risk Score for CVD (GRS) proposed by D'Agostino et al., ${ }^{14}$ they found a $20.1 \%$ prevalence of high CVR; by using the GRS as reference, the authors evaluated the accuracy of two other CVR scores: the Hard Coronary Heart Disease Framingham Risk Score, ${ }^{15}$ which found a prevalence of high CVR of $4.5 \%$, and the simplified Global Risk Score (sGRS), which found a prevalence of $20.7 \%$. In conclusion, the authors emphasize

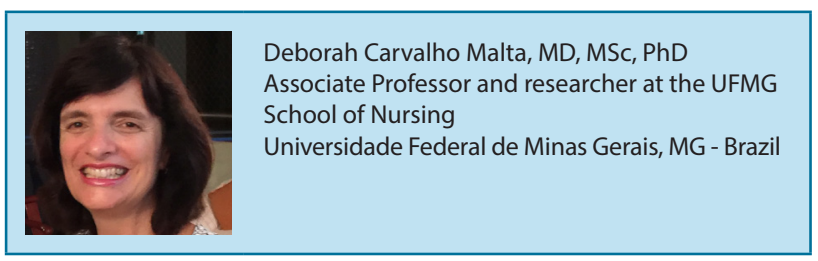


two aspects of their work: 1) the high CVR of these socially vulnerable women living in Quilombos; and 2) the potential of applying the sGRS in primary care settings due to its higher discriminatory power, evaluated by the receiver operating characteristic (ROC) curve (area under the curve $[\mathrm{AUC}]=0.98$; 95\%CI: 0.98-0.99), and its simplicity, as it uses the body mass index instead of total and HDL cholesterol. ${ }^{11}$

Regarding the first aspect, a recent study by Malta et al. (2021) $)^{1}$ used laboratory data of 8953 individuals aged $>18$ years from the National Health Survey (NHS) containing glycated hemoglobin, cholesterol, and blood pressure measurements. By applying the GRS, the study identified high CVR in $8.7 \%$ of women aged 30 to 74 years. The prevalence of high CVR increased with age and reflected social inequality, as it was higher in the least educated population (15.7\%; 95\% CI 13.5-18.3) and among Black women (14.4\%; 95\% CI 9.7-20.9). ${ }^{1}$ As such, this study revealed a higher prevalence of high CV $\mathrm{R}$ than that reported by Cavalcante et al.,11 probably because younger women were included in the latter. ${ }^{11}$ In this context, we need to recognize that high CVR was found in women aged 19 to 59 years (56\% $<40$ years), since the strongest predictor of CVR in any risk equation is age. In fact, Cavalcante et al. ${ }^{11}$ found that, when stratified by age, the prevalence of high CVR was 10 times higher among women aged 40-49.9 years and 30 times higher in women $\geq 50$ years. It is important to note that the evaluation of the lifetime risk of CVD, in addition to the 10-year risk, should be considered for younger individuals to overcome this limitation. ${ }^{16}$

Regarding the second aspect, the use of the sGRS in primary care would indeed allow easier CVR assessment, which is an excellent characteristic for a screening tool and should prompt its promotion. Another suggestion by Cavalcante et al. is to use the information promptly available in primary care to calculate CVR, such as previous examinations or blood pressure measurements. Malta et al. ${ }^{17}$ highlight how differences between CVR scores can derive from different aspects: the eligible population, predictors, and the weight of each predictor and/or outcomes (Table 1). ${ }^{17}$ Finally, the cut-offs recommended by CVR calculators differ and are arbitrarily defined. ${ }^{17}$ These divergences can confuse clinicians and result in misperceptions of risk and difficulties in implementing public policies, as emphasized in other international ${ }^{18}$ and national ${ }^{17}$ studies. In Brazil, the prevalence of individuals aged 45 to 64 years classified as intermediate or high CVR using data from the NHS had a large variation, from $2.5 \%$ (95\%CI 1.8-3.3) to $44.1 \%$ (95\%CI 39.7-47.3), according to which of the six scores was used. ${ }^{18}$

The definition of the best calculator to be implemented depends on the aim of the study. Some scores calculate only the risk of cardiovascular deaths, while others include non-fatal cardiovascular events. ${ }^{13}$ According to Malta et al., 17 "the choice for which CVR calculator

Table 1 - Characteristics of selected risk scores for the primary prevention of cardiovascular disease

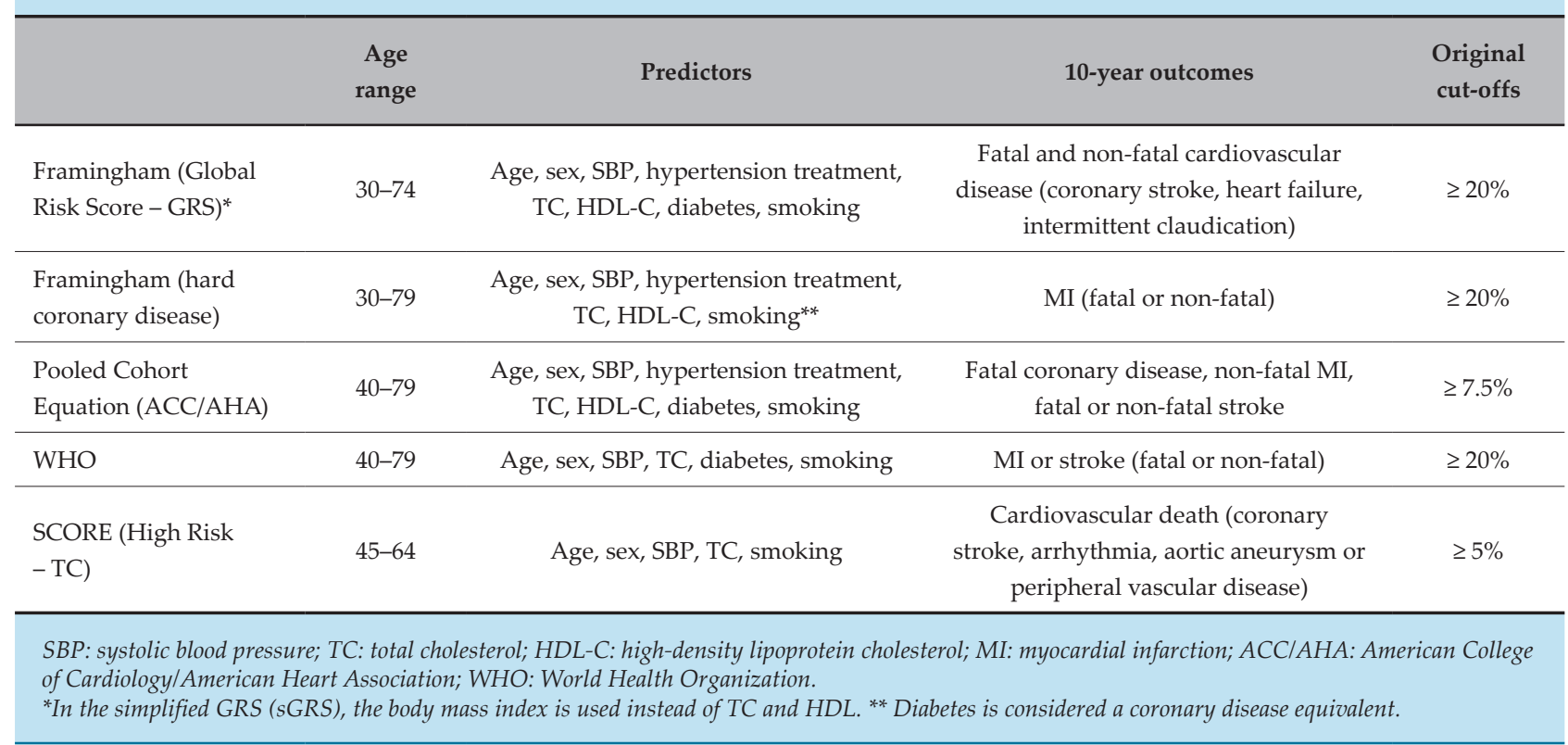


should be used in Brazil is under debate, in the sense that there is no equation derived from a study conducted in the Brazilian population that considers the characteristics of our population, such as the racial composition, socioeconomic and geographic conditions." For that, longitudinal data evaluating MACE are needed but are not yet available in the country. ${ }^{19}$

Lastly, while identifying individuals with high CVR is important, population-wide strategies that promote a healthy lifestyle benefit all individuals, independently of their CVR, and are particularly relevant for socially vulnerable populations. ${ }^{20}$ The WHO sets forth actions for the promotion of health, such as regulatory measures including the taxation of tobacco products, alcohol, and ultra-processed foods ${ }^{21}$ and the creation of environments that render accessible and encourage healthy choices such as physical activity and healthy diets. ${ }^{7,21}$ While mass preventive strategies are more politically challenging, particularly in a scenario of low investment in health, they need to be combined with strategies focused on individuals at high CVR to improve the cardiovascular health of all Brazilians. ${ }^{22}$

\section{References}

1. Malta DC, Pinheiro PC, Teixeira RA, Machado IE, Santos FMD, Ribeiro ALP. Cardiovascular Risk Estimates in Ten Years in the Brazilian Population, a Population-Based Study. Arq Bras Cardiol. 2021;116(3):42331. doi: $10.36660 / a b c .20190861$

2. Santos IS. "Know the Enemy and Know Yourself". Cardiovascular Risk in the National Health Survey. Arq Bras Cardiol. 2021;116(3):432-3. doi: $10.36660 /$ abc. 20210105 .

3. World Health Organization. Global Health Estimates 2016: Disease Burden by Cause, Age, Sex, by Country and by Region, 2000-2016. Geneva: World Health Organization; 2018.

4. Nascimento BR, Brant LCC, Oliveira GMM, Malachias MVB, Reis GMA, Teixeira RA, et al. Cardiovascular Disease Epidemiology in PortugueseSpeaking Countries: Data from the Global Burden of Disease, 1990 to 2016. Arq Bras Cardiol. 2018;110(6):500-11. doi: 10.5935/abc.20180098.

5. Oliveira GMM, Brant LCC, Polanczyk CA, Biolo A, Nascimento BR, Malta DC, et al. Cardiovascular Statistics - Brazil 2020. Arq Bras Cardiol. 2020;115(3):308-439. doi: 10.36660/abc.20200812.

6. Harper S, Lynch J, Smith GD. Social Determinants and the Decline of Cardiovascular Diseases: Understanding the Links. Annu Rev Public Health. 2011;32:39-69. doi: 10.1146/annurev-publhealth-031210-101234.

7. World Health Organization. Global Action Plan for the Prevention and Control of NCDs 2013-2020. Geneva: World Health Organization; 2013.

8. Global Burden of Disease Study 2019 (GBD 2019) results. Global Health Data Exchange website. Seattle, WA: Institute for Health Metrics and Evaluation (IHME), University of Washington; 2019.

9. World Health Organization. Global NCD target prevent heart attacks and strokes through drug therapy and counselling. Genebra: World Health Organization; 2016

10. Simão AF, Precoma DB, Andrade JP, Correa FH, Saraiva JF, Oliveira GM, et al. I Brazilian Guidelines for Cardiovascular Prevention. Arq Bras Cardiol. 2013;101(6 Suppl 2):1-63. doi: 10.5935/abc.2013S012.

11. Cavalcante AL, Ferreira HS. Accuracy of the Simplified Version of the Global Risk Score in Detecting Cardiovascular Risk in Women from Quilombola Communities in the State of Alagoas, Brazil. Int J Cardiovasc Sci. 2021; 34(4):358-368. doi:https://doi.org/10.36660/ijcs.20210068

12. Arnett DK, Blumenthal RS, Albert MA, Buroker AB, Goldberger ZD, Hahn EJ, et al. 2019 ACC/AHA Guideline on the Primary Prevention of Cardiovascular Disease: A Report of the American College of Cardiology/

American Heart Association Task Force on Clinical Practice Guidelines. Circulation. 2019;140(11):596-646. doi: 10.1161/CIR.0000000000000678.

13. Silverman MG, Ference BA, Im K, Wiviott SD, Giugliano RP, Grundy SM, et al. Association Between Lowering LDL-C and Cardiovascular Risk Reduction Among Different Therapeutic Interventions: A Systematic Review and MetaAnalysis. JAMA. 2016;316(12):1289-97. doi: 10.1001/jama.2016.13985.

14. D'Agostino RB Sr, Vasan RS, Pencina MJ, Wolf PA, Cobain M, Massaro JM, et al. General Cardiovascular Risk Profile for Use in Primary Care: the Framingham Heart Study. Circulation. 2008;117(6):743-53. doi: 10.1161/ CIRCULATIONAHA.107.699579.

15. Expert Panel on Detection, Evaluation, and Treatment of High Blood Cholesterol in Adults. Executive Summary of The Third Report of The National Cholesterol Education Program (NCEP) Expert Panel on Detection, Evaluation, And Treatment of High Blood Cholesterol in Adults (Adult Treatment Panel III). JAMA. 2001;285(19):2486-97. doi: 10.1001/jama.285.19.2486

16. Lloyd-Jones DM, Leip EP, Larson MG, D'Agostino RB, Beiser A, Wilson PW, et al. Prediction of Lifetime Risk for Cardiovascular Disease by Risk Factor Burden at 50 Years of Age. Circulation. 2006;113(6):791-8. doi: 10.1161/CIRCULATIONAHA.105.548206.

17. Malta DC, Pinheiro PC, Azeredo RT, Santos FM, Ribeiro ALP, Brant LCC. Prevalence of High Risk for Cardiovascular Disease Among the Brazilian Adult Population, According to Different Risk Calculators: A Comparative Study. Cien Saude Colet. 2021;26(4):1221-31. doi: 10.1590/1413-81232021264.01592021.

18. Bazo-Alvarez JC, Quispe R, Peralta F, Poterico JA, Valle GA, Burroughs $\mathrm{M}$, et al. Agreement Between Cardiovascular Disease Risk Scores in Resource-Limited Settings: Evidence from 5 Peruvian Sites. Crit Pathw Cardiol. 2015;14(2):74-80. doi: 10.1097/HPC.0000000000000045.

19. Schmidt MI, Duncan BB, Mill JG, Lotufo PA, Chor D, Barreto SM, et al. Cohort Profile: Longitudinal Study of Adult Health (ELSA-Brasil). Int J Epidemiol. 2015;44(1):68-75. doi: 10.1093/ije/dyu027.

20. Rose G. Strategy of Prevention: Lessons from Cardiovascular Disease. Br Med J. 1981;282(6279):1847-51. doi: 10.1136/bmj.282.6279.

21. World Health Organization. "Best Buys" Tackling NCDs: Best buys and other recommended interventions for the prevention and control of noncommunicable diseases. Geneva: World Health Organization; 2017.

22. Brant LCC, Ribeiro ALP. Cardiovascular Health: A Global Primordial Need. Heart. 2018;104(15):1232-3. doi: 10.1136/heartjnl-2017-312562. 